\title{
EL SURGIMIENTO DEL PROBLEMA DE LA LIBERTAD EN LA MODERNIDAD BURGUESA. SU FORMULACIÓN EN LEIBNIZ
}

\author{
THE EMERGENCE OF THE PROBLEM OF FREEDOM IN THE \\ BURGOSA MODERNITY. FORMULATION IN LEIBNIZ
}

\section{Roberto Ayala Saavedra*}

\section{RESUMEN}

Libertad y Determinismo definen los términos de un problema instalado en el centro del debate intelectual desde los inicios de la modernidad. Las relaciones entre la subjetividad y el mundo objetivo, la acción y la estructura, remiten al núcleo problemático, la principal cuestión de fundamentos, junto al de la historicidad de las ciencias sociales. El objetivo de este trabajo es examinar el abordaje y los aportes realizados en este campo por uno de los más grandes pensadores de la modernidad, G. Leibniz.

PALABRAS CLAVE: LIBERTAD * DETERMINISMO * LEIBNIZ * MODERNIDAD

\section{SUMMARY}

Freedom and Determinism define the terms of a problem fixed at the center of intellectual debate since the beginning of modernity. The relations between subjectivity and the objective world, action and structure, refer to the problematic center, the main question of foundations, together with that of historicity of the social sciences. The objective of this work is to examine the approach and the contributions made in this field by one of the greatest thinkers of modernity, G. Leibniz.

KEYWORDS: FREEDOM * DETERMINISM * LEIBNIZ * MODERNITY 


\section{INTRODUCCIÓN}

Libertad y Determinismo definen los términos de un problema instalado en el centro del debate intelectual desde los inicios de la modernidad. Las relaciones entre la subjetividad y el mundo objetivo, la acción y la estructura, la voluntad y el sistema, $y$ la ausencia de acuerdo, remiten al núcleo problemático, la principal cuestión de fundamentos, junto al de la historicidad, de las ciencias sociales. El objetivo de este trabajo es examinar el abordaje y los aportes realizados en este campo por uno de los más grandes pensadores de la modernidad, G. Leibniz.

En la historia del pensamiento, la noción de libertad adquiere diversos sentidos y usos: como posibilidad de autodeterminación, como posibilidad de elección, como acto voluntario, como espontaneidad, como margen de indeterminación, como ausencia de interferencia, como liberación frente a algo, como liberación para algo, como realización de una necesidad (Ferrater, 1977). Puesto en términos generales, se puede afirmar que la noción, desde su origen, apunta en dos direcciones fundamentales: a) la libertad como ausencia de interferencia $y$ b) la libertad como capacidad de autorrealización. Ambas suponen la posibilidad del sujeto cognoscente, que en la medida que es dotado de la capacidad de discernir y de conocer, puede entonces elegir (racionalmente, según sus necesidades $y$ aspiraciones) $y$ por tanto, ha de enfrentar las consecuencias derivadas de tal potestad.

En el medioevo, los autores cristianos, habiendo incorporado en parte el legado greco-romano, se esfuerzan por colocar el problema en un marco ideológico-cultural sustancialmente distinto: el del conflicto entre la libertad humana y la denominada predestinación o, al menos, presciencia divina. En el intento de conciliar los términos del dilema, la acentuación presuntamente excesiva de alguno de los polos, terminaban por conferirle un status insatisfactorio a los más diversos intentos, induciendo la recurrente apertura de la cuestión.

Es pues en este contexto intelectual - específicamente el de las controversias del cristianismo medioeval, renovadas por el renacimiento y la reforma- que se aborda el tema del lugar del libre albedrío en la obra leibniziana. Puesto en breve, ¿cómo es posible integrar la libertad y el poder de la persona humana (del sujeto burgués) en un mundo definido a partir de la noción de armonía preestablecida? El tratamiento de Leibniz no consigue superar el dilema, pero constituye un avance en su abordaje, tanto en sus derivaciones epistémicas - las distinciones necesidad, contingencia, posibilidad, orden libre-, como en sus contenidos temáticos: la introducción de un rudimento, una intuición de la historicidad en la interpretación de los asuntos de los seres humanos; todo ello como síntoma de los procesos más generales del despliegue y consolidación de la modernidad burguesa. Esto es lo que a continuación se propondrá explorar.

\section{ALGUNOS ANTECEDENTES}

En el pensamiento cristiano, la cuestión de la libertad del ser humano adquiere una significación decisiva en la medida que coloca en juego la cuestión del lugar y papel de la divinidad en el orden de las cosas. El misterio de las relaciones entre un supremo creador, dotado de todas las perfecciones, y su creación, el ser humano, entidad limitada, imperfecta, $y$ sin embargo, de alguna manera, expresión cimera de Su arte, representa un enigma de principal importancia para la estructura doctrinaria del cristianismo. Si se entiende el discurso religioso como un momento decisivo del mecanismo de regulación de la vida social —en la época en cuestión- se puede comprender la magnitud de la relevancia del dilema $y$ de sus posibles resoluciones en relación con la eficacia de tal discurso para controlar $y$ ordenar las tensiones sociales, de las que, por otra parte, es expresión, en cierto sentido.

Un ser humano absolutamente autónomo no precisa y por tanto puede prescindir de la 'hipótesis' de dios; ni siquiera moralmente lo requiere puesto que la historia parece registrar, ya entonces, códigos morales y 'hombres buenos $y$ justos' que lo son sin referencia a una autoridad extramundana. Pero el ser humano no es, ni puede ser, y por supuesto, no debe asumirse como en la visión cristiana, completamente autónomo debido a que su naturaleza ha sido fundamentalmente 'corrompida por el pecado original'. Tal primigenia condición lo torna inclinado al mal, de manera que, a partir de aquí, lo que sorprenderá es que el libre albedrío pueda 
ser usado para realizar algún bien. El buscar y hacer el bien entra así a depender de la 'gracia' divina: el 'justo' es inspirado y hasta guiado por dios; no lo es por sí mismo, ya que según su naturaleza, no obraría más que el mal. Una forma de 'escepticismo antropológico'.

La ambivalencia doctrinal instala la disputa sobre la cuestión del status de la libertad en el ser humano. Un primer antecedente, en el pensamiento cristiano, lo constituye Pablo de Tarso, al postular que "no el bien que quiero, sino el mal que no quiero hago" (La Biblia, Romanos, 7:19). Se trata de una visión en la que conviven en forma particular, tanto la afirmación de la omnipotencia de dios como la aceptación de una cierta libertad en el ser humano; pero en un contexto marcadamente pesimista, cruzado por el mito del pecado original y su gravitación en la determinación de la conducta de la criatura humana. Junto a la proclamación de la predestinación divina de los elegidos, aparecen la exigencia por la contribución del propio esfuerzo $y$ el reconocimiento del valor de las obras para la salvación. De estos últimos aspectos se apartaran Lutero y todos aquellos que en el ulterior desarrollo del pensamiento cristiano habrán de inclinarse por la afirmación cuasi absoluta de la gracia o la moción divina, contándose entre estos, el jansenismo ${ }^{1}$.

Durante la fase de la transición entre el renacimiento y la modernidad propiamente, Descartes introduce un nuevo concepto de hombre mediante la deposición del mito eclesiástico, dominante en el medioevo europeo, de la divina ordenación de todas las cosas; este nuevo hombre asume los atributos de libertad ética y poder técnico. La libre voluntad, determinada por el entendimiento, se transforma en un elemento central en su sistema: su amplitud es, por lo menos subjetivamente, tan grande como la libre voluntad de dios. "Nuestra voluntad quiere o rechaza las cosas, según el entendimiento las califique de buenas o malas; basta

1 Ver "La filosofía agustiniana de la historia”. Giner, S. (1994). Historia del pensamiento social. Ed. Ariel. Barcelona. Pág. 129. Sobre el Jansenismo, consultar Abbagnano, N. (1973) Historia de la filosofia. Ed. Montaner y Simón. Barcelona. Págs. 105 y 222. juzgar bien para obrar bien, y juzgar lo mejor que se pueda para hacer lo mejor, para adquirir las virtudes $y$ con ellas los otros bienes asequibles a nuestra voluntad" (Descarte, 1992, p. 19).

Otro tanto ocurre con la noción de acción. La idea de la acción humana exige cierta autonomía en el actor, sugiere al menos la existencia de una intención; la voluntad del sujeto que conoce, que es substancia conocedora, se constituye en un elemento de importancia por demás comprensible en un cuerpo de doctrina en el cual la subjetividad encuentra un rol decisivo. Sin la intención, el actor deviene un simple acontecimiento en la cadena de la causalidad que reina en el orden del mundo mecánicamente organizado.

Todo esto en el marco del dualismo cartesiano de la mente/cuerpo, el cual si por un lado le permite proponer un margen de discrecionalidad ética en el uso por la persona humana de su libre albedrío, por otro, le obliga inevitablemente a buscar alguna forma de acomodar su concepto de libertad, de voluntad libre, de intención en el actor, a un orden necesario del cosmos, orden matemáticamente fundado y compuesto a la manera de una gran máquina. La libertad parece transformarse entonces en una necesidad de ajustar la propia acción a las posibilidades efectivas presentes en el orden del mundo. Es la libertad y el poder del dominio de sí propio. Pese al dualismo ontológico, el voluntarismo tiene que adecuarse a la posibilidad racional.

En Spinoza, la libertad no se desliga de las leyes de la necesidad universal, es la necesidad comprendida. Así se establece con toda claridad una de las tradiciones del pensamiento moderno en relación con la cuestión que aquí nos ocupa, la que considera que la libertad consiste fundamentalmente en 'seguir la propia naturaleza' (el racionalismo naturalista ha de ser leído como momento de la destrascendentalización; la noción de libertad se construye contra el providencialismo). Considerar a Spinoza partidario de una forma de determinismo negador de la libertad, es una simplificación burda. Derivando hacia una metafísica materialista, $y$ en acuerdo con su psicología de las sensaciones, Hobbes dirá, por su vez, que 'la vida no es más que un movimiento de miembros'. Mecanicismo, determinismo y la 
noción de Ley le orientan en un sentido objetivista; de esta manera la libertad deviene ausencia de un obstáculo exterior al movimiento. Estas concepciones tienen el mérito de socavar el dogma teocéntrico, abriendo el camino para una consideración racional y científica de los problemas.

Se puede afirmar que tales autores de alguna manera representan los puntos altos del clima ideológico-cultural, en el cual Leibniz respira $y$ a partir del cual deberá elaborar su propia aproximación al problema del libre albedrío. Clima que aparece polarizado entre el mecanicismo-matematización de la naturaleza $y$ la tendencia profundamente experimentada por la mayor parte de los pensadores de la época de liberar al sujeto, conocedor, creador o moral: se está ante la emergencia progresiva de una de las mayores aportaciones de la modernidad occidental, la subjetividad en tanto que factor dinámico del mundo, en tanto que parte del mundo.

\section{LEIBNIZ Y LA LIBERTAD}

Puesto en términos muy generales, se podría decir que la aproximación de Leibniz al problema pasa por el intento de conciliar la presciencia con la libertad. El gran pensador busca integrar en una totalidad sistémica, el conjunto de los elementos presentes en el universo, en la creación; su erudita formación, que le permite considerar en forma simultánea planos o facetas distintas de un mismo problema -metafísico, físico, lógico, ético, político-, hace con que advierta la pertinencia, a distintos niveles, de ambos términos de la cuestión. Para Leibniz se trata de salvar la libertad de iniciativa, $y$ por tanto, la responsabilidad, de la criatura humana, sin hacer de cómplice del desconocimiento de la omnisciencia y omnipotencia de dios. Para ello, pone el énfasis en el depender de sí mismo (es el espíritu el que define los motivos y elige entre diversas posibilidades, siguiendo una regla moral finalista, procediendo según el racional principio de lo mejor); pero en tanto que la mónada espiritual, por disposición divina, se encuentra 'preñada del propio futuro'. Fórmula lo suficientemente problemática como para admitir más de una lectura interpretativa, pero que de toda forma introduce el concepto de la persona como autoresponsable de sus actos, decisiones, escogencias: el futuro del individuo se encuentra, de alguna manera, en él mismo. El problema resurge, sin embargo, tan pronto algún comentador llama la atención sobre el hecho de que tal futuro remite a una 'naturaleza', lo cual ciertamente plantea con toda legitimidad la sospecha de que se esté hablando en realidad de una extrema forma de determinismo, en el sentido de necesitarismo.

Más específicamente, se puede apreciar esta forma de abordar el problema en su metafísica noción de la sustancia individual, a la cual atribuye libertad y contingencia, pero también aquellos atributos considerados necesarios, esto es, los elementos constitutivos sin los cuales la sustancia no sería ella misma. Así, por ejemplo, que Cesar cruce efectivamente el Rubicón es un evento que depende de una elección o decisión de tal substancia-sujeto, $y$ las consecuencias que se deriven de la verificación de un tal acontecimiento sobre ella recaerán, con entera justicia pues este es un ámbito en el que se despliega la libertad de Cesar. Por el contrario, el hecho de que Cesar sea una substancia dotada de un alma inteligente, que su condición sea la de una criatura racional, esto remite a un atributo necesario, puesto que la idea o naturaleza de Cesar, en su condición de ser humano, implica, incluye necesariamente la capacidad del pensar racional.

La dificultad o paradoja a la que hacíamos referencia anteriormente se manifiesta aquí en el hecho de que, en los términos de la teoría de la substancia de Leibniz, al portar en sí misma la substancia-sujeto Cesar todo su pasado, presente $y$ futuro, $y$ desde toda la eternidad, resulta que si bien el actuar de Cesar depende del propio Cesar en cuanto substancia autónoma, este comportamiento se encuentra implicado en la idea de esta substancia-sujeto desde siempre. Dicho de otro modo, aunque los acontecimientos que marcan la vida de Cesar poseen un carácter contingente, esto es, que sus respectivos contrarios no implican contradicción y por tanto, no son lógicamente necesarios, que se verifiquen en la vida de una substancia-sujeto, $y$ en un orden específico, es completamente seguro desde siempre. Y tan solo puede haber una única substancia en la cual aquel conjunto de eventos $y$ esta secuencia se verifiquen: Cesar. En perfecto acuerdo con ello, se encuentra el criterio 
de que una sola, si se quiere infinitesimal, variación en el conjunto de acontecimientos que pueblan el despliegue de una substancia individual basta para caracterizar a una substancia diferente, a una persona que ya no sería Cesar. Puesto que Cesar, para serlo, ha de cruzar el Rubicón. Y el no hacerlo, eventualidad lógicamente considerada como un posible real puesto que se habla aquí de una contingencia, implica, en el sistema de Leibniz, que estamos frente a una substanciasujeto distinta de la de Cesar. Es a esta singularidad absoluta de la substancia a la que Leibniz se refiere con el principio de la identidad de los indiscernibles: dos o más substancias absolutamente indiscernibles no pueden más que ser la misma substancia (Leibniz, 1977).

Tratar de arrojar alguna luz sobre el dilema libertad/necesidad en Leibniz no es seguramente una empresa sencilla. En lo que sigue se revisan algunos de sus más conocidos textos a fin de examinar la posibilidad de esbozar algún criterio al respecto. Adelanto el criterio interpretativo desarrollado: Leibniz no tiene éxito en solucionar el dilema porque este no tiene solución. La libertad humana no es reconciliable con la idea de predestinación, o con la mera existencia del trascendente. Pero el que pese a su ferviente teísmo sienta la necesidad intelectual de acomodar la libertad humana, es sintomático del espíritu del tiempo. Y esto es lo fundamental, desde nuestro punto de mira: Leibniz elabora un problema central de su tiempo, del despliegue de la modernidad, no importa con cuanta consciencia, y esa elaboración reopera como un factor, discursivo, del proceso. La problemática solución de Leibniz quiere salvar ambos, el imperio de dios y la libertad humana. Así, todo lo que ocurre, está desde siempre en la mente de dios; pero para la criatura es el fruto contingente de sus decisiones. Según la metafísica teológica, no hay verdadera libertad. Pero para todos los efectos de este mundo contingente, el individuo es libre y responsable. Y esta es otra forma, junto a la de Spinoza, de hacer irrelevante a dios... Leibniz contribuye al alumbramiento del sujeto burgués.

\section{EL DISCURSO DE METAFÍSICA}

El 'pequeño discurso' de 1686, marca el inicio de la segunda etapa en la evolución de la reflexión en Leibniz, la llamada etapa sistemática. Luego al comienzo, en el apartado 3 del texto, el autor entrega un concepto de libertad definida con relación a la razón: "Creen también que con esto dan más realce a la libertad de dios, como si no fuera el mayor grado de libertad el obrar con perfección según la razón soberana”. Solo el supremo entendimiento obra de acuerdo con el grado sumo de libertad pues solo él tiene en sí, de manera eminente, la visión exhaustiva de las posibilidades disponibles $y$ por tanto, opera no sujeto a ninguna limitación. En contraposición, la libertad del ser humano es de un tipo muy inferior ya que su entendimiento es de un grado también inferior, solo parcialmente claro y menos aún distinto; es la condición natural de un espíritu finito: la libertad en función de la potencia del entendimiento.

Por otro lado, se afirma que en virtud del decreto divino que establece la inclinación de la criatura racional a obrar en el sentido del bien aparente, lo cual se entiende en el sentido de la tendencia del ser humano a expresar o imitar la voluntad de dios, Él estaría determinando nuestra voluntad a la elección de lo que parecería ser lo mejor, 'pero sin cohibirla', sin constreñirla; esto es, la voluntad decretoria genera en el ser humano una inclinación, una suerte de tendencia, en la criatura, pero, $y$ he aquí lo realmente decisivo, esta inclinación no determina absolutamente, no porta el carácter de lo necesario. Y esto, porque, dice Leibniz, "absolutamente hablando, el alma está en la indiferencia en cuanto esta se opone a la necesidad, $y$ tiene el poder de obrar de otra manera o de suspender por completo su acción, siendo $y$ permaneciendo posible el seguir uno $u$ otro camino". De modo que en este punto del Discurso nos encontramos frente a un Leibniz claramente comprometido con la preservación de un margen significativo para el arbitrio libre en el ser humano: "Depende, pues, del alma, el precaverse contra las sorpresas que pueden causar las apariencias, empleando una voluntad firme $y$ reflexiva, $y$ no obrando ni juzgando en ciertas ocasiones, sino después de haber maduramente deliberado". Afirmar la capacidad humana de ejercer control efectivo sobre el actuar, tiene como uno de sus resultados más 
notables el salvar la dimensión moral del sujeto responsable. Pero, además, en Leibniz, este actuar autónomo, base de la responsabilidad moral, a fin de obrar el bien, ha de sostenerse en la razón, en una voluntad que se quiere no caprichosa, o incluso inspirada en altos valores, sino reflexiva.

Con todo ello, se está aquí en el centro de uno de los debates que habiendo animado los medios teológico/filosóficos medioevales, es recogido y renovado por los autores de la reforma y contrarreforma. Leibniz asume una postura, en el pasaje citado, que parece aproximarlo a aquellos que, como Erasmo, en su 'De Libero Arbitrio', asumen una defensa moderada (por oposición a un pelagianismo extremo) del libre albedrío: "Concibo aquí el libre albedrío como un poder de la voluntad humana por medio del cual el hombre puede consagrarse a las cosas que conducen a la salvación eterna o puede apartarse de ellas". No hay aquí una afirmación de un libre arbitrio absolutamente autónomo y decisivo, puesto que se parte del reconocimiento del poder $y$ la necesidad de la gracia. De igual forma se puede establecer la relación, al menos conceptual, con la doctrina molinista (Luis de Molina) del concurso simultáneo.

Simultáneamente, el criterio expuesto por Leibniz en el pasaje supracitado lo opone inevitablemente al luteranismo, para el cual la doctrina de la afirmación del poder de la voluntad humana equivalía a una negación de la gracia divina. La afirmación por Lutero de la eficacia absoluta de la causalidad divina, en el contexto de una cruda renovación del debate acerca de los derechos de la voluntad libre $y$ de la predestinación, configura un determinismo cuasi absoluto de dios sobre la criatura. Para él, sencillamente, la presciencia y la moción divinas determinan necesariamente la voluntad del hombre, la cual por otra parte $-y$, en realidad, esta sería la razón de aquello- se encontraría corrompida por el pecado original. Criterio este último de largo arraigo en el pensamiento cristiano. Se trata de una visión en la que campea un pesimismo marcado, cruzado por un profundo sentimiento del pecado y su gravitación en la determinación de la conducta de la criatura humana. Solo la intervención de la gracia y la moción divina, y no una pretendida voluntad libre, pueden evitar el que el ser humano incurra en el pecado, que se pierda.

Volviendo al texto de Leibniz, interesa destacar que al afirmar que la inclinación divina es al 'bien aparente', a lo que 'pareciera lo mejor', la referencia implícita a la imperfección de la criatura derivada de su condición de espíritu finito remite al hecho de que su entendimiento limitado puede llevarlo, $y$ de facto es lo que ocurre con gran frecuencia, al error, a incurrir en el mal moral, en el pecado.

Dios está moralmente obligado a la elección de lo mejor, apunta Leibniz en otro pasaje, $y$ es debido justamente a ello que crea al ser humano libre, puesto que esta es la única forma de que el bien moral acceda a la realización. Una criatura absolutamente determinada por la moción divina, no alcanzaría mérito alguno en su obrar, por la razón precisamente de que no sería responsable. Pero simultáneamente, al concederle el ser libre, tiene la divinidad que permitir el mal, del cual entonces no es culpable sino quien lo elige, quien abusa de la libertad recibida para realizar el bien. Por ello sostiene "que no se tiene el derecho a quejarse; que no hay que preguntar por qué peca Judas, dado que esta acción libre está comprendida en su noción...”.

Luego entonces, el pecado, o su posibilidad, aparece como una suerte de precio que debe pagar la criatura por el don de la libertad recibido de la sabiduría divina. Para la divinidad, en cambio, la presencia del mal siquiera sería una fuente de desazón; el pecado no es más que uno de los rasgos constitutivos de la criatura, implicado o presente en su noción, en tanto que espíritu finito, naturaleza portadora de privación. Noción, idea o naturaleza metafísica que, además, no es dependiente de la voluntad divina, sino que, 'está en dios', habita su entendimiento, en un mundo de verdades eternas; de ahí el que habitualmente se caracterice la posición de Leibniz como 'intelectualismo', por oposición a un voluntarismo que coloca en la cuenta de una voluntad $y$ un poder perfectos, absolutos, la creación de todo lo existente $y$, por supuesto, de la persona humana, con sus perfiles específicos; mundo de las ideas cuyas notorias resonancias platónicas encuentran corroboración en distintos pasajes de la obra leibniziana. 
De manera que el obrar se le aparece a Leibniz, desde el punto de vista del ser humano, libre, no constreñido, aunque, dice, inclinado, a lo aparentemente mejor; como quiera que sea, aquí se hace presente un reconocimiento de la intervención divina, $y$ esto coloca la cuestión de su esclarecimiento, la pregunta por el carácter, condiciones y alcances de la intervención divina. Esto lo aleja de la postulación de alguna voluntad absolutamente libre o autónoma. Dice, en el apartado 30 del texto que nos ocupa: "Al concurrir Dios a nuestras acciones ordinariamente, no hace más que seguir las leyes que ha establecido, es decir, conserva y produce continuamente nuestro ser, de suerte que los pensamientos nos llegan espontánea o libremente en el orden que la noción de nuestra substancia individual permite, $y$ en el que se podría prever de toda eternidad". Si bien a un ocasionalista podría agradar, en principio, la aserción según la cual 'dios concurre a nuestra acciones ordinariamente', acto seguido Leibniz le deja a la vera del camino al reducir tal concurso a la estructura legal sobre la cual el supremo arquitecto ha elegido, a partir de las consideraciones insuperables y perfectas de su supremo grado de sabiduría y de su obligación moral a actuar lo mejor, pasar a la existencia al mundo posible efectivamente actualizado, este, 'el mejor de todos los posibles'.

La divinidad produce y conserva nuestro ser, pero lo hace en el marco regulatorio definido por las leyes que ordenan el funcionamiento y el movimiento del mundo físico. Un jansenista podría sospechar, con cierta razón, que en este aserto asoma un cierto perfil spinoziano en Leibniz. Porque si dios concurre a nuestras acciones sobre la base de las leyes 'que el mismo ha establecido', esto en la práctica puede venir a significar que, una vez creado, el mundo se ve limitado a seguir, legal y contingente, $y$ por toda la eternidad, su curso, al aliento eso sí del primer impulso divino ${ }^{2}$. Entre otros efectos, esto conllevaría

2 En LA TEODICEA, págs. 23-24, Leibniz reitera su punto de vista: "Pero yo no admito lo sobrenatural aquí más que en el principio de las cosas, respecto de la primera formación de los animales o respecto de la constitución originaria de la armonía preestablecida entre el alma y el cuerpo; después de lo cual yo creo que la formación de los animales y la ausencia de un monarca, reduciendo la calidad de la divinidad a la dimensión de mero creador, de arquitecto.

En otros pasajes de su obra Leibniz claramente toma distancia de tan extrema, $y$ en sus tiempos aún peligrosa, conclusión; pero lo que aquí nos interesa principalmente es examinar lo que podría constituir el 'núcleo fuerte' de la reflexión leibniziana acerca del asunto en cuestión, al margen de sus contradicciones, incluso posibles concesiones o prudencias.

Subsiste, respecto de la cuestión de las relaciones entre libertad $y$ determinismo o necesitarismo, el problema de que en el pasaje aludido, Leibniz si bien establece la autonomía de la substancia individual, incluso en el nivel de sus pensamientos, que le llegarían en forma libre y espontánea, subordina tal autodeterminación al marco de un orden incorporado en y permitido por la noción de la substancia, y que, por consiguiente, podría ser conocido desde toda la eternidad por un observador portador de un entendimiento lo suficientemente poderoso, claro y distinto, situación que es sólo la de la divinidad. Es la noción lógica de la substancia, portadora en sí misma de todos sus predicados, de todo lo que le acontece y que se puede afirmar con toda seguridad a su respecto. La intuición de lo histórico parece bloqueada por un logicismo que, en la opinión de algunos comentaristas constituye el aspecto central y más interesante de la obra de Leibniz (Russell, 1947). Es este un problema sobre el que se volverá más adelante.

En el mismo apartado 30 del DISCURSo, una vez establecido el amplio ámbito en el que rige la libre voluntad humana, Leibniz, fiel a su orientación más general, intenta una vez más equilibrar su posición aplicándose a la cuestión del papel de la gracia divina. Es aquí donde apunta uno de los conceptos claves de su reflexión filosófica. En relación con el problema del origen del mal, dice: “...se ve claramente que Dios no es la causa del mal. Porque, no sólo después de la perdida de la inocencia de los hombres a causa del pecado original, sino que ya antes había una limitación

la relación entre el alma y el cuerpo son algo tan natural al presente como las demás operaciones más ordinarias de la naturaleza". 
o imperfección original, connatural a todas las criaturas, que las hace pecables o capaces de delinquir". La razón, pues, de que el mal sea en el mundo, el mejor de todos los posibles, es la propia naturaleza metafísica de la criatura, la privación o limitación que es su marca, tal como Agustín y otros autores han hecho ver, dice. Y los efectos negativos inevitablemente derivados de esta limitación los "remedia Dios graciosamente por el grado de perfección que le place conceder" (a cada uno). Lo más interesante en este pasaje, desde el punto de vista de nuestro asunto, es que acto seguido Leibniz sostiene que esta gracia divina, teniendo su grado y medida, y siendo siempre eficaz por sí misma para producir cierto efecto proporcionado, "es además siempre suficiente, no sólo para librarnos del pecado, sino también para producir la salvación", suponiendo que el hombre ha de ayudarse por su parte.

De modo que incluso cuando Leibniz se pliega a una posición de cierto compromiso con posturas más claramente inclinadas a la postulación de la eficacia absoluta de la causalidad divina, aún en estos momentos se permite dejar una portezuela abierta, adjuntar una cláusula, cuyo sentido es salvar, aunque sea en últimas, su noción de la libertad humana. Y esto es lo que con toda claridad aparece en el pasaje anterior, donde Leibniz acaba haciendo depender a la eficacia de la gracia divina de la disposición - puesto que se trata de una cuestión de voluntad personal: "aquí sólo se trata de no querer", o también "obrad según vuestro deber que conocéis bien"- del ser humano de esforzarse en pos de unos ciertos objetivos, el buscar el bien, o lo que aparenta al menos serlo, librarse del pecado o, más grave aún, alcanzar la salvación. Y si alguna duda persistiera, podemos leerlo afirmando explícitamente las limitaciones de la gracia en la determinación de la conducta de la criatura racional: "pero no siempre es suficiente (la gracia) para sobreponerse a las inclinaciones del hombre, porque de otra manera no tendría objeto". Claro, porque si la criatura humana no fuese sino una pura expresión de la divinidad, que sería el caso si la gracia fuese absolutamente eficaz y consiguiese determinar completamente el actuar humano, entonces, ¿qué sentido tendría el distinguir el obrar de la criatura de la voluntad y la gracia divinas? Para que el problema de la eficacia de la gracia tenga algún sentido es preciso reconocer al ser humano algún grado de autonomía. La gracia absoluta, completamente eficaz, siempre victoriosa, dice Leibniz, rige solo en la divinidad, vale para dios.

\section{LA TEODICEA}

Veinticuatro años después del DISCURSo, sale a la luz un trabajo de considerable extensión en el cual el filósofo se propone expresamente, y así lo hace indicar ya en el subtítulo, volver sobre los problemas de la libertad humana y el origen del mal: LA TEODICEA, o 'justificación de dios', un ensayo de teología racional. En nuestros días, uno podría preguntarse que puedan tener en común una exploración metafísica tendiente a la justificación de dios con el estudio de la libertad en el ser humano. Por supuesto que los términos en que se ventila cualquier problema están histórico-culturalmente condicionados. La respuesta, me parece, presenta una gran utilidad para entender el pensamiento de nuestro filósofo en sus aspectos más profundos, interesantes y perdurables. En la reflexión de Leibniz, como en toda la corriente racionalista, la cuestión, en parte teológica, en parte metafísica, de dios, el 'dios' de los filósofos', no puede ser obviada, pero puede adquirir diversos sentidos: 'justificar a dios' parece querer significar aquí un intento de hacerlo compatible con la libertad en el ser humano, poner en armonía la omnisapiencia y omnipotencia divinas con una criatura que, subrayemos, es autónoma porque es racional; siendo esta racionalidad un atributo definitorio, una condición necesaria de la noción de ser humano. Por ello, los temas centrales de LA TEODICEA, más allá de todo lo relacionado con la esencia y existencia de la divinidad, son dios, el mundo y el ser humano, el mal, el destino y la gracia, predeterminación y libertad.

Luego en el prefacio de la obra, resulta interesante notar que Leibniz, en su aproximación introductoria y panorámica a los problemas que se propone considerar, se vale de una forma de expresarse que de cierta manera preanuncia la perspectiva o punto de vista desde el 
cual pretende hallar soluciones a los enigmas bajo examen. Dice: "mientras obedecemos a la razón y cumplimos nuestros deberes, (...) cuando dirigimos nuestros propósitos al mayor bien, que no difiere en nada de la veneración de dios, encontramos que nada corresponde mejor a nuestro propio interés que trabajar por los intereses de la generalidad"; y también, "Sin embargo, antes que él nos dé a conocer su voluntad por medio de los acontecimientos, debemos tratar de salir a su encuentro, haciendo todo aquello que parezca convenir más con sus mandamientos". Obedecer a la razón, cumplir con los deberes correspondientes, dirigir los propósitos, nuestro propio interés, salir al encuentro, etc., todo parece claramente apuntar hacia una reafirmación de la existencia autónoma de la criatura, en un contexto dominado por la creciente secularización de la vida social. Incorporar todo ello en un marco literario cuyo objetivo declarado es el de abordar la justificación de la divinidad cristiana, puede muy bien no ser más que el ineludible tributo que ha de reconocer - conscientemente o no, en realidad eso es de una importancia menor- la innovación, en un complejo momento histórico de transición sociocultural.

Un detalle adicional en el pasaje seleccionado: la divinidad nos da a conocer su voluntad por medio de los acontecimientos. No se trata de una frase suelta, se sabe del énfasis leibniziano en la regularidad sistémica del universo, en el orden al que nada escapa; si a la voluntad divina se la asimila al transcurrir regular de lo real eventual-contingente, entonces alguien podría legítimamente colocarse la cuestión acerca del carácter prescindible de la hipótesis de dios en, al menos, algunos de los aspectos centrales de la reflexión leibniziana.

En el apartado 8 del prefacio de LA TEODICEA, Leibniz da inicio a su discusión acerca de lo que ya ha denominado 'la magna cuestión de la libertad $y$ de la necesidad'. Comienza refiriéndose a la cuestión de la, por los antiguos denominada, dice, 'razón perezosa'; la cual consiste en el falso razonamiento que conduce a no hacer nada, "o por lo menos a no preocuparse por nada y a dejarse llevar por nuestra inclinación a gozar de los placeres del momento. Pues, se decía, si lo que ha de suceder, ha de suceder necesariamente, lo que ha de acaecer, acaecerá, hágase lo que se haga”. La razón de tal forma de ver, explica Leibniz, reside en que se concibe el futuro como necesario, sea porque la divinidad todo lo ha previsto y lo predetermina hasta en sus mínimos detalles sea porque todo sucede por una cadena pretendidamente necesaria de causas y efectos, etc. En todo caso, la verdad de los acontecimientos futuros está determinada por dios, en cuanto él es la causa primera de todo lo que ocurre, el autor de toda causa, $y$ quien por tanto ha previsto todos los efectos. Para Leibniz esta noción de destino, a la que llama 'fatum mahometanum', no pasa, en cuanto aplicación a la realidad, en cuanto criterio o guía de la conducta, de una falsa representación de la necesidad.

En este asunto se deja ver una vez más la fe intelectualista de Leibniz, por ejemplo, cuando afirma que quien se entrega a la razón perezosa, que se inclina ante acontecimientos considerados fatales, lo hace con el propósito de evitarse 'el mal rato de la reflexión'. Se trata otra vez de la imagen de una criatura que es libre porque es racional, y que al renunciar al ejercicio de tal facultad, $y$ asumir una actitud fatalista frente al devenir, simplemente renuncia a esa libertad, tornándose en un esclavo de acontecimientos que no comprende ni mucho menos controla; tal sería, dice, "la fuente de las ceremonias supersticiosas de la hechicería, en la cual algunos hombres tienen tanta fe (...), porque constituiría el camino más corto y más descansado para alcanzar la felicidad".

Toda la discusión acerca de la necesidad de rechazar la llamada 'fatalidad del destino', encuentra su justificación en su relación con el problema de la dimensión moral de la criatura racional: "sin tener malas intenciones... se pueden considerar de otro modo las extrañas consecuencias de una necesidad fatal; considerando que destruirá la libertad de arbitrio, tan esencial a la moralidad de la acción; porque la justicia y la injusticia... la pena y la recompensa no podrían tener lugar con relación a las acciones necesarias, $y$ nadie podría ser obligado... a no hacer lo que es necesario" (Prefacio, apartado 14, p. 11). Estamos ante uno de los momentos intelectuales de la emergencia de la figura de 
la subjetividad autónoma, del yo individual, del sujeto racional, activo, autodeterminado y responsable, característico de la modernidad burguesa.

En el inicio de la primera parte de LA TEODICEA, Leibniz reafirma su criterio o punto de vista fundamental respecto de la cuestión de la libertad en el ser humano. Refiriéndose a los asuntos sobre los que se extenderá en esta primera gran sección de la obra, dice: "Las dificultades pueden ser divididas en dos clases. Las unas nacen de la libertad del hombre, que parece incompatible con la naturaleza divina; y sin embargo la libertad se juzga necesaria para que el hombre pueda ser juzgado culpable y castigado" (p. 96). Modo muy hábil de argumentar si se considera, insistimos, el clima cultural y político en el que se mueve el filósofo, tanto en el campo protestante como en el del partido papista (Confesión de Augsburgo, jansenistas, etc.).

El apuntar a la cuestión de la culpa y el castigo, como forma de hacer ver la necesidad de reconocer cierto derecho a la acción libre de la criatura racional, parece revelar el interés de Leibniz de mostrar lo que considera el error en que incurren ciertas corrientes de interpretación teológica del pensamiento cristiano contemporáneo, pero tomándoles la palabra, en cierto sentido, mediante la incorporación de algunos de los temas que les son más caros. Como quiera que sea, el punto a destacar aquí reside en su clara y expresa intención de apuntalar la dimensión ética del ser humano. Dentro de la lógica y el contenido sustancial de su doctrina, esto se justifica por su concepción de que un mundo en el cual los humanos no dispusiesen de libertad, no podría ser el mejor de los mundos posibles. Una criatura racional dotada de arbitrio libre debe ser admitida a la existencia por la voluntad decretoria, de acuerdo siempre con el principio de que dios está moralmente obligado a escoger lo mejor, $y$, en este caso, tal eventualidad, y no la que se le opone, la de una criatura heterónoma y absolutamente determinada por la causalidad divina, representa, sin lugar a dudas para Leibniz, el mayor bien.
Tal posición lo contrapone a aquellos, por ejemplo, 'ciertos cartesianos modernos', que pretenden que dios es el único actor, $y$ las criaturas no son más que sus órganos puramente pasivos. La peligrosa consecuencia de ello, se esfuerza por hacer ver Leibniz, es que las cosas se ven dispuestas de modo que el ser humano parece verse obligado a obrar el bien y el mal que hace " $y$, por consiguiente, que no merece por ello ni castigo ni recompensa; lo que destruye la moralidad de las acciones y repugna a toda justicia divina y humana" (p. 97). El detalle de la incorporación de la necesidad de salvar los derechos de la justicia humana, que no solo de la divina, resulta también revelador de las motivaciones profundas, socioculturalmente arraigadas, que operan subyacentemente en el pensamiento discursivo de Leibniz; se trata de una preocupación de raíz claramente moderna, vinculada con el proceso histórico de surgimiento y consolidación del Estado moderno y de toda la superestructura político-institucional e ideológica de la nueva época social que por entonces muy trabajosamente todavía se va abriendo paso.

Más adelante, en otro pasaje de la obra, Leibniz se ocupa más específicamente del estatuto de la libertad en la criatura. Dice creer que la voluntad humana además de verse exenta de coacción, también lo está de necesidad; refuerza su punto de vista apoyándose en Aristóteles, quien, dice, afirmó la existencia en la libertad de dos aspectos, espontaneidad y elección, "y es en esto en lo que consiste nuestro imperio sobre nuestros actos" (p. 122). Cuando obramos libremente nadie nos fuerza, ni se nos impide tener el espíritu libre cuando deliberamos, afirma. "Hay contingencia en mil acciones de la naturaleza, pero cuando el juicio no está en el que obra, no hay libertad. Y si tuviéramos un juicio que no fuese acompañado de ninguna inclinación a obrar, nuestra alma sería un entendimiento sin voluntad" (p. 122). La criatura libre conlleva la criatura racional, capaz de juzgar, pero además no se trata de una criatura que obre o juzgue mediante una voluntad de equilibrio, para la cual tanto dé una cosa que otra, al menos en aquellos asuntos de cierta gravedad. Obramos mediados por una voluntad 
que se ve inclinada. Por decreto divino, obramos mediante una voluntad que tiende al bien en general, que "debe ir hacia la perfección que nos conviene, y la suprema perfección está en Dios" (p. 121). El decreto divino, sin embargo, ya se sabe, inclina sin constreñir, permite que el individuo tienda a buscar el bien aparente, que se le reclame el hacer de acuerdo con su deber, el buscar vivir de acuerdo con los mandamiento de dios, base del criterio y la normativa morales imperantes en su época. De ahí el rechazo a la noción de la indeterminación o indiferencia llamada de equilibrio. Un tal equilibrio en todos los sentidos es, dice imposible, no solo lógicamente, también empíricamente imposible, puesto que la experiencia indica que siempre hay una razón o causa que nos ha inclinado hacia la opción seleccionada, hacia el partido escogido.

La dificultad principal reside en el hecho de que la verdad de los futuros contingentes, la acción del individuo, por ejemplo, está determinada desde toda la eternidad: no solo se contempla aquí la noción de la substancia que porta en sí todo lo que de ella se podrá predicar, y que por tanto posee en sí misma todo su pasado, presente y futuro, sino que además está, todo este futuro contingente, presente en forma eminente en el entendimiento de dios, en 'la región de las verdades eternas'. "Ya era verdad hace cien años que yo escribiría hoy". Que la ocurrencia de los futuros contingentes sea segura desde siempre, no impide que permanezcan contingentes, puesto que hay una diferencia, dice Leibniz, entre el ser cierto y el ser determinado, a pesar de que muy frecuentemente se lo tome por una misma cosa. Más precisamente lo que se confunde indebidamente es aquello que está determinado a ocurrir, por la misma naturaleza de la verdad, y que por ello no podría perjudicar a la libertad, con esto otro que se denomina de verdad necesaria; al implicar contradicción con su contrario, esto último, significa la imposibilidad de tal contrario. En contraste, la certidumbre de la ocurrencia de un contingente - en el entendimiento de dios o en la noción de la substancia individual dada, porque en el entendimiento humano solo hay un reconocimiento a posteriori de tal verdad- no obsta que su contrario permanezca perfectamente posible, desde un punto de vista lógico.

Empírico-históricamente, todo transcurre en dependencia del arbitrio libre, de la libertad de acción, de juicio y de elección de cada uno de los individuos; por supuesto que, en el criterio de Leibniz, con posterioridad, los acontecimientos acaban revelándonos cuál es el curso de acontecimientos que hacen a mi noción en cuanto substancia individual, como a un sujeto unos predicados. Más brevemente: la existencia que se despliega contingentemente ante $y$ para nosotros, existe desde siempre y por toda la eternidad en la mente de dios. Así se salvan tanto la presciencia del creador como la libertad de la criatura. Edad media teocéntrica $y$ modernidad burguesa trenzadas en una lucha aún abierta. Lo nuevo es la lucha, y en ella, el sujeto autónomo se abre duramente paso.

La conclusión de lo anterior nos lleva a que la presciencia divina no hace a la verdad más determinada, o sea necesaria. La verdad de los futuros contingentes es prevista porque es determinada; pero no es verdadera porque sea prevista en dios. La omnisapiencia divina no se opone a la libertad del individuo. Y en esto, declara Leibniz estar de acuerdo con el partido de los 'defensores de la ciencia media' (molinistas), en contra de los predestinadores. Con los que sin embargo dice solidarizarse en la cuestión del reconocimiento de que la preordinación de dios, con sus decretos y toda la serie de causas que de ellos se desprenden, sí que contribuye a la determinación de la voluntad de la criatura. El conciliador ha querido una vez más congraciarse con los dos bandos enfrentados, buscando asignarles cuotas razonables de acierto en la controversia. Cierto, pero no demasiado, puesto que a renglón seguido, el filósofo agrega que su acuerdo con los 'predeterminadores' incluye la clausula siguiente: "siempre que la predeterminación no es necesitante", lo cual es justamente lo que buena parte de los predestinadores agustinos y dominicos vienen de defender.

De modo que lo contingente no se rige por el principio de contradicción, el que dice que de dos proposiciones contradictorias, necesariamente, una es verdadera y la otra falsa; sino que lo hace por lo que Leibniz llama el 
principio de razón determinante o suficiente (apartado 44). Se puede afirmar a priori que de todo lo que existe se puede dar, o al menos es posible encontrar, una razón de por qué algo es como es y por qué no es como no es, o de por qué existe esto más bien que otra cosa. "Este gran principio se da en todos los acontecimientos, $y$ no encontraremos nunca un ejemplo en contrario" (p. 128), y eso aunque las más de las veces tales razones determinantes nos sean desconocidas ${ }^{3}$.

Aplicando todo el razonamiento anterior a la cuestión de la voluntad, resulta que hay siempre una razón prevalente, determinante, que inclina a la voluntad a su elección, " $y$ basta, para conservar su libertad, que esta razón incline sin necesitar". Y cuando se dice que jamás estamos necesitados a hacer lo que hacemos, se refiere Leibniz a una necesidad que llama metafísica o absoluta, regida por el principio de contradicción, aunque ya sabemos que en un cierto sentido sí actuamos bajo un tipo de necesidad inclinante, por ejemplo, hacia el bien aparente; es lo que el filósofo denomina de necesidad hipotética o moral. De la misma forma que dios se encuentra inclinado a escoger $y$ hacer siempre lo mejor por una necesidad que es solo moral.

Hay pues una libertad en el ser humano, incluso si se quiere esta puede ser denominada de libertad de indiferencia, siempre que por indiferencia se entienda que nada nos obliga a obrar en este o aquel sentido, a favor de tal o cual partido. Lo que, en el parecer de Leibniz, no resulta en lo absoluto aceptable es la noción de la indiferencia absoluta o de equilibrio, que todo resulte simétricamente igual de un lado y de otro, puesto que, de acuerdo con el principio

3 "Nuestros razonamientos están fundados sobre dos grandes principios: el de contradicción, en virtud del cual juzgamos falso lo que implica contradicción, $y$ verdadero lo que es opuesto o contradictorio a lo falso, [...] y el de razón suficiente, en virtud del cual consideramos que no podría hallarse ningún hecho verdadero o existente, ni ninguna enunciación verdadera, sin que haya una razón suficiente para que sea así y no de otro modo. Aunque estas razones en la mayor parte de las cosas no pueden ser conocidas por nosotros". MONADOLOGIA. Párrafos 31 y 32, pág. 392. supracitado de razón determinante, si todo obedece a alguna razón o causa, conocida o no, poco importa para los efectos presentes, también los desarrollos de la voluntad han de poder adscribirse a alguna razón válida. Y tal, y no otro, es el contenido del aserto que postula la inclinación de la voluntad: la indiferencia de equilibrio no es más que un obrar sin razón. Es por ello, también, que el caso del Asno de Buridán no es factible en la naturaleza, en el mundo. No hay dilema fáctico o disputa de valor que la razón no pueda dirimir. Buridán es un asno, no una criatura racional.

\section{LA MONADOLOGÍA}

Opúsculo redactado en 1714, la MONADOLOGIA presenta, en cierto sentido, un muy apretado, aunque preciso, compendio del estado definitivo o final alcanzado por la reflexión de nuestro autor. Si bien es de general aceptación el reconocimiento de que el opúsculo registra cambios, leves, de su pensamiento, en punto tanto a terminología como a doctrina, en realidad, ocurre que en el ámbito temático de nuestro interés las enmiendas, si alguna hay, lucen menos que leves. En el apartado 30, el autor vuelve sobre uno de sus temas clásicos en la caracterización de la sustancia humana, a saber, el atributo del ser racional de la criatura. Ya sabemos que la criatura para ser libre tiene que ser racional. Aquí, Leibniz insiste en que el conocimiento de las verdades eternas es lo que nos distingue de los animales $y$ nos hace poseedores de la razón, lo cual permite que nos elevemos hasta el conocimiento de nosotros mismos y de dios. Y esto es lo que define a lo que denomina 'alma razonable' o espíritu. Ampliando un poco el tema, dice que este acceso cognoscitivo a las verdades necesarias condiciona el que alcancemos el nivel de los actos reflexivos por medio de los cuales podemos "pensar en lo que llamamos el yo y considerar que esto o aquello se halla en nosotros" (1977, p. 392). Y así, al pensar en nosotros, nos constituimos en una suerte de sujeto cognoscente, autoconsciente $y$ conocedor, del ser, la substancia, incluso de dios mismo. La capacidad reflexiva nos da los objetos de nuestros razonamientos, incluyendo el 'sí mismo' como objeto; razonamiento que 
posibilita la facultad del juzgar, la cual justamente se encuentra en la base de todo actuar libre. Si es que se puede decir de esta manera, el núcleo del ser es, así, racionalidad. La racionalidad de la criatura, su noción, implica su capacidad de libre deliberar y obrar.

Posteriormente, al referirse a la diferencia entre las almas ordinarias y los espíritus, el autor reitera que lo que consigue particularizar de forma decisiva a los segundos es que, además de ser espejos vivientes o imágenes del universo, estos son "imágenes de la Divinidad misma, o del mismo Autor de la naturaleza". Portadores de la capacidad de conocer el sistema del Universo, incluso de reproducirlo, o 'imitarlo', en sus obras, cada espíritu es como una pequeña divinidad en su ámbito de acción. El cuerpo de la criatura, a la que Leibniz llama 'materia segunda', esto es, un conjunto o constelación de las partes obscuras de aquellas mónadas congregadas en seres complejos, se encuentra de alguna forma unido a una mónada superior, justamente el alma o mónada dominante, especie de núcleo luminoso que dirige y coordina la acción, en la cual la apercepción adquiere la profundidad y alcance de la autoconsciencia, lo que quiere decir que de cierta forma participa, aún cuando sea de forma limitada, de atributos también presentes, pero en su grado sumo de perfección, en la divinidad. Y esta es también una forma, alegórica, tal vez, pero no por ello menos contundente, de afirmar la autonomía de la criatura racional, que, asimilada a la condición de pequeña divinidad, o, mejor aún, de dios en pequeño, se nos aparece dotada, ciertamente en grado y perfección menor, de algunos de los atributos principales del supremo creador y monarca.

Finalmente, en los últimos apartados de la MONADOLOGÍA, precisamente los que se ocupan de la 'la ciudad de dios', la cual es definida como un mundo moral en el mundo natural (ideal de comunidad humana), Leibniz alerta que en ella "los pecados deben llevar consigo su penitencia, por orden de naturaleza y en virtud de la estructura mecánica de las cosas”. Y, de la misma forma, las acciones buenas obtendrán su recompensa, y por la misma vía natural, sin violentar el orden mecánico del mundo.
Esta 'ciudad de dios', pues, admite el pecado, y en un marco regulatorio dado por la naturaleza terrena; $y$ todo ello remite a un mundo de criaturas finitas, afectadas de privación, sujetas al error $y$, en el pensamiento leibniziano, libres. Además, claro está, de la explícita referencia a una criatura racional que ha de soportar los cargos de responsabilidad derivados de su proceder, sean estos recompensas o castigos, penas o gratificaciones. Y ya sabemos que en el universo conceptual leibniziano la reivindicación de la posibilidad de culpabilidad en el ser humano no es sino un recurso dirigido a apuntalar la argumentación en favor y respaldo de la libertad en la persona.

\section{DISCUSIÓN Y ALGUNAS CONCLUSIONES}

La defensa de la libertad humana en la reflexión leibniziana tiene, como ya se ha mencionado antes, un alto precio: se trata nada menos que de la posibilidad del pecado, el que dios permite, pero del cual no es responsable. Su razón está dada por la imperfección esencial de la criatura, su carácter de naturaleza deficiente; $y$ no podría ser de otra forma puesto que dios no puede crear sino criaturas limitadas: "O Dios no crea nada, o tiene que crear seres limitados". La mónada creada no puede portar o poseer todas las perfecciones de la mónada increada; una divinidad que crea divinidades en realidad no hace más que crearse a sí misma, si se considera, según el concepto de Leibniz, que al ser indiscernibles se constituyen en identidades, en la mismidad. Luego entonces, la criatura, al carecer de las excelencias supremas, es deficiencia, está sujeta al error, al mal moral; muy a pesar de su inclinación al bien aparente, pues, es pecable.

Pero todo ello solo es posible porque posee libertad, si estuviese absolutamente determinada por la causalidad divina, siendo entonces nada más que una manifestación de la voluntad decretoria, no podría perderse, y por lo tanto no tendría que padecer las miserias derivadas de su imperfecta condición, tanto de entendimiento como moral. Pero en la medida en que está dotada de un juicio libre y razonable, puede ejercer control sobre su actuar, procurar vivir con arreglo a los dictámenes de 
la moral, que en Leibniz adquiere la fisonomía ideológico-cultural de una moral teológica, vivir intentando 'cumplir con su deber'.

Más allá de la forma teológico-metafísica del discurso, estamos aquí ante un barrunto de antropología racional, humanista, antecedente de lo histórico-concreto, de una noción del ser humano en cuanto ser social, históricamente configurado y configurador. Puesto en otros términos, la visión de Leibniz, con independencia de sus propósitos conscientes, tiende a constituir conceptualmente a un individuo funcionalizado respecto de las nuevas exigencias sociales colocadas por los procesos que atraviesan la época histórica de transición en la cual le ha tocado vivir. Desde un punto de vista socioantropológico, es una contundente forma de justificar su título de filósofo de la modernidad occidental; uno de los momentos intelectuales decisivos del ascenso del sujeto burgués. Sin sujeto libre no hay reconocimiento de la historicidad; el sujeto libre es la Historicidad (poniendo entre paréntesis los límites y contradicciones de esa ‘sujetivación' en el mundo capitalista).

Paradoja de aún mayor contextura tal vez, en el pensamiento leibniziano, es la representada por la teoría de la substancia, en sus relaciones con el problema de la libertad. Se trata de un problema de particular complejidad, sobre las que solo se puede aquí expresar algunas, fundadas, interpretaciones. Dos aspectos de la mencionada teoría, me parece, guardan una particular relación con nuestro asunto, a saber, la noción lógica de la substancia y la concepción acerca de la historia del espíritu finito. En primer lugar, notar que, en el DISCURSo, Leibniz, al iniciar la discusión acerca de la noción de substancia individual, puntualiza el hecho de que es a esta substancia individual a la que propiamente pertenecen tanto la pasión como la acción, dato de relevancia porque estos caracteres son, obviamente, elementos necesarios de la noción de la criatura libre. A renglón seguido, en este apartado (8), define a la substancia individual como aquel sujeto al cual se le atribuyen muchos predicados y "este sujeto no se atribuye a ningún otro”. Más adelante, dice que la naturaleza de un ser completo o substancia individual consiste en "tener una noción tan acabada de él, que baste para comprender y deducir de ella todos los predicados del sujeto a quien se atribuye esta noción" (1977, p. 12). Un ser dotado del grado supremo de inteligencia, al contemplar la noción de un individuo completo cualquiera, 'vería', en conjunto, ordenada pero atemporalmente, todos los eventos que en su vida le acaecerían a este individuo: en cierto sentido, el sujeto es sus predicados.

Es por ello que, segundo, más adelante en el mismo DISCURSo, Leibniz puede afirmar que "Hemos dicho que la noción de una substancia individual encierra de una vez para siempre todo lo que puede suceder a ésta, y que, atendiendo a esta noción, puede verse en ella todo lo que es posible enunciar con verdad de aquella..." (1977, p. 15). La noción de toda substancia individual porta en sí todo su pasado, presente $y$ futuro. La pregunta de rigor es, entonces, ¿cómo encaja en este cuadro definido a partir de la teoría de la substancia la dimensión libre de la criatura racional? Ello porque, evidentemente, el actuar y juzgar libre suponen un ámbito de contingencia, solo reconocible en su verdad, para la criatura, con posterioridad: 'dios nos revela su voluntad en los acontecimientos'. Luego, ¿es libre el individuo, esto es, construye activamente su futuro? o, antes bien, ¿se encuentra toda su existencia, $y$ de toda eternidad, predeterminada en su noción, que es decir en el entendimiento de dios, de cuya voluntad $y$ poder ha dependido, además, el que un ser completo haya logrado ser admitido a la existencia? ¿Cómo compatibilizar la noción lógica de la substancia con el carácter mundano del individuo? Si se considera que Leibniz está permanentemente yendo $y$ viniendo, moviéndose en planos distintos, desde una naturaleza metafísica, las filoplatónicas regiones de las verdades eternas, a un mundo físico-moral, mecánicamente regido. Por ejemplo, cuando dice que está perfectamente de acuerdo con lo segundo, desde que no se olvide que sus fundamentos últimos, esenciales, residen en el primero de los planos. Claro que entonces el problema no hace sino desplazarse a la cuestión de las formas concretas de armonización de los planos: es la sabiduría de dios, responde, la que, mediante su bondad, voluntad y poder, ha decidido que este 
mundo terrenal se rija de esta forma y no de una otra cualquiera. Esto puede no satisfacer a muchos, pero el hecho es que su resultado, en el contenido doctrinario, es salvar la libertad de la criatura. Se trata de mostrar no la consistencia sino la pertinencia del pensamiento de Leibniz. Tal incongruencia es el precio y el paradójico camino que hizo posible la decisiva relevancia histórica de su pensamiento. Y hay que ver el enorme talento desplegado en el intento de imposible sutura de la disonancia. El equilibrismo entre los dogmas teológicos de la época, un dogmatismo ferozmente represivo, $y$ las nuevas ideas promovidas, estimuladas, por las nuevas condiciones. El sujeto burgués se abre camino. Leibniz muere dos años después de la publicación de LA FABULA DE LAS ABEJAS de Mandeville.

Por otro lado, puede intentarse resolver la paradoja afirmando que si bien el mundo en el que el individuo se debate se encuentra, para él $y$ en su nivel de entendimiento, abierto, esto es, sujeto a su capacidad de hacer, y condicionada esta por su talento en el ejercicio del juicio racional, no deja de ser cierto que su 'personalidad', su singularidad, su yo, se encuentra relacionalmente (sobre)determinado por el conjunto de los eventos que pueblan y, en realidad, hacen su vida, en una progresividad continua, marcada por las contingencias que le acaecen; la forma de responder a cada uno de estos eventos, y su conjunto, lo individualizan, haciéndolo discernible, único. Libertad y subjetividad individual, dos atributos del ser humano, surgidos o recuperados por la renovación ideológico-cultural de la modernidad. Examinados con posterioridad, los acontecimientos que han marcado el rumbo de la vida de un individuo, y que, por supuesto, han operado como determinantes en su resultado provisional, se le aparecen con una especie de necesidad hipotética, en el lenguaje de Leibniz. Y, a futuro, se sabe que unos sucesos adicionales, no conocibles a priori, con entera seguridad modificarán, agregándose, tal provisionalidad, también necesaria por hipótesis respecto de este resultado, que no es otra cosa sino la noción de una substancia individual. Pero, lo verdaderamente interesante aquí es que nada de esto impide que este futuro abierto ha de ser pasional, activa y racionalmente construido por el individuo libre, por lo cual ha de asumir toda la responsabilidad, y es por ello que "no hay que quejarse de la suerte ni responsabilizar a dios'. El mundo en que el individuo se mueve es una construcción social, un resultado de la actividad del conjunto de los seres humanos. Las posibilidades de libertad son una construcción social.

Dentro de los límites del presente examen de la cuestión de la libertad del ser humano en Leibniz, creo que la hipótesis interpretativa a la que podemos arribar consiste en que se puede encontrar un considerable monto de evidencia que indica la presencia en su reflexión filosófica de una clara contribución a la noción y la causa de la autonomía de la criatura racional y libre, en las condiciones de la época.

\section{REFERENCIAS}

Abbagnano, N. (1973). Historia de la Filosofía. Barcelona: Montaner y Simón.

Descartes, R. (1992). Discurso del Método. III Parte. México: Porrúa.

Ferrater, M. J. (1977). Diccionario de Filosofía. Tomo II. Buenos Aires, Argentina: Sudamericana.

Giner, S. (1994). Historia del pensamiento social. Barcelona: Ed. Ariel.

Leibniz, G. (s.f). La Teodicea. Madrid, España: M. Aguilar.

Leibniz, G. (1977). Discurso de Metafísical Monadología. México: Porrúa.

Russell, B. (1947). Historia de la Filosofía Occidental. Vol. II. Buenos Aires, Argentina: Espasa-Calpe.

Fecha de ingreso: 07/11/2017 Fecha de aprobación: 10/07/2018 
